\title{
A Preliminary Exploration of the Gulf Stream System with SOFAR Floats
}

\author{
William J. Schmitz, Jr., James F. Price, Philip L. Richardson, \\ W. BRechner OWens and Douglas C. WebB, \\ Woods Hole Oceanographic Institution, Woods Hole, MA 02543 \\ Robert E. Cheney \\ Goddard Space Flight Center, NASA, Greenbelt, MD 20771 \\ H. THOMAS RossBY \\ Graduate School of Oceanography, University of Rhode Island, Kingston 02881
}

(Manuscript received 5 December 1980, in final form 3 June 1981)

\section{ABSTRACT}

SOFAR (sound fixing and ranging) floats deployed for engineering tests during 1977-79 yield the first long-term quasi-Lagrangian observations in the subsurface Gulf Stream System. The character of these float tracks supports the premise that the Gulf Stream is a persistent, large-scale, vertically coherent jet at depths (approximately) within and above the main thermocline, where mean and eddy kinetic energies are roughly the same and lateral motions of the Stream are clearly delineated. A float track at thermocline depth is visually coherent with the track of a concurrently launched surface drifter over the larger horizontal scales traversed during the first few months of their trajectories. Below thermocline depths, fluctuation or eddy kinetic energies are normally larger than the mean and a persistent Gulf Stream is difficult to detect. However, deep motions that are visually coherent with upper level flows may be observed for an intermediate range of space and time scales.

Eddy kinetic energies based on the float data are compatible with existing Eulerian estimates to the extent comparable. The consistency of a quasi-Lagrangian eddy kinetic energy estimate in the vicinity of the thermocline, roughly $400 \mathrm{~cm}^{2} \mathrm{~s}^{-2}$, the first such observation to our knowledge, is indirect but relatively convincing. Zonal and meridional variances for the float data are also in line with existing Eulerian results. Estimates of the frequency distribution of eddy kinetic energy for the longest float trajectory available are nearly identical to comparable Eulerian results at frequencies less than about a cycle per 20 days.

\section{Introduction}

The nature of the Gulf Stream System has been a subject of intense inquiry and frequent controversy throughout the history of oceanography, and remains so to this day (Clarke et al., 1980; Fofonoff, 1981; Hendry, 1981; Schmitz, 1977, 1978, 1980; Stommel, 1965; Worthington, 1976). For the first time, neutrally buoyant (SOFAR) floats have been deployed and tracked acoustically over relatively long times and distances in the vicinity of the Stream. These floats, launched primarily as engineering tests of tracking capability, were positioned from data obtained from both land-based and moored listening stations. The purpose of this note is to present a preliminary description of results based on the five subsurface trajectories obtained, along with a contemporaneous surface drifter path. We first examine the cohesive nature of the flow in the thermocline and upper layers of the Gulf Stream, relative to the more chaotic flow observed near the Stream at abys- sal depths, where perturbation (or eddy) kinetic energies are normally larger than the mean. We then focus on estimates of eddy energy levels. At depths below the thermocline, this, the first such intercomparison in the vicinity of the Gulf Stream, yields quasi-Lagrangian perturbation kinetic energy levels and an associated frequency distribution that are remarkably compatible with those based on Eulerian data.

\section{Background}

Neutrally buoyant, acoustically tracked floats were initially developed by Swallow $(1955,1957)$ and subsequently used in a variety of influential observational programs, all based on shipboard tracking. Prominent examples are the first direct measurements identifying an abyssal undercurrent along the western boundary of the North Atlantic (Swallow and Worthington, 1961), and results from the ARIES Expedition that initially demonstrated the existence 
of a comparatively energetic mesoscale eddy field in the North Atlantic southwest of Bermuda (Crease, 1962; Swallow, 1971). The short-term float observations at abyssal depths conducted during Gulf Stream ' 60 (Fuglister, 1963) led Worthington (1976) to postulate a vertically coherent and persistent Gulf Stream with relatively large abyssal currents in the same direction as in the upper layers, leading to a consequently large transport. However, the persistence of a Gulf Stream at abyssal depths has not been easy to reconcile with the relatively large-amplitude timedependent currents that have consistently been observed there over the last decade or so, beginning with Fofonoff (1967) and Schmitz et al. (1970). The existence of the largest eddy kinetic energies (per unit mass, hereafter understood, symbol $K_{E}$ ) at all depths in the vicinity of the Stream is now one of the most clearly established properties of the eddy field in the western North Atlantic. These results suggest that abyssal currents near the Gulf Stream cannot always be visualized as part of a vertically coherent structure. Long-term float observations for examination of the typicality of the (roughly) week-duration data obtained at abyssal depths during Gulf Stream ' 60 have been needed for some time.
Floats that can be tracked from shore stations over long distances with lifetimes of a few years were developed by Rossby and Webb (1970) and by Rossby et al. (1975). These SOFAR floats were first used in quantity in a mid-ocean dynamics experiment (Freeland et al., 1975; McWilliams, 1976). Several floats were deployed in Gulf Stream rings shortly thereafter (Cheney et al., 1976), and some later moved into the Gulf Stream, but were followed there for short periods of time only (roughly two weeks). SOFAR floats were next used in quantity in the western basin of the North Atlantic both south and north of the MODE area (McDowell and Rossby, 1978; Price and Rossby, 1981; Riser et al., 1978; Riser and Rossby, 1981). The recent development of moored (Autonomous) Listening Stations (ALS's; Bradley, 1978) removes the limitations on the area of operation imposed by land-based tracking.

Many surface drifters have been tracked in the Gulf Stream System in recent years (Kirwan et al., 1976; Richardson et al., 1979; Richardson, 1980, 1981). These paths provide clear evidence for the persistence and large horizontal scale of the upper level Stream west of the Grand Banks. Drifter trajectories have been observed to be strongly influenced

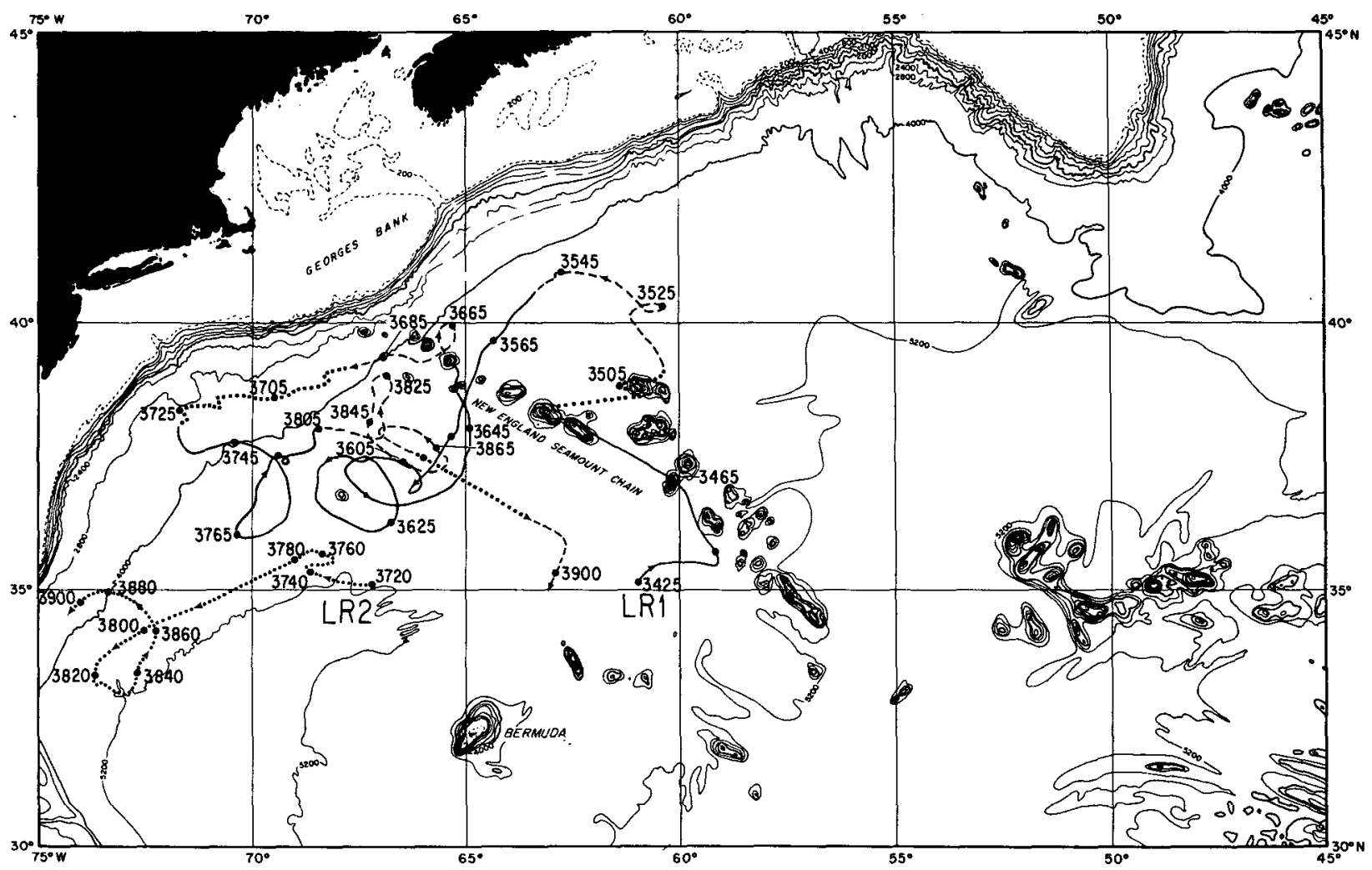

FIG. 1. Trajectories for floats LR1 and LR2, as indicated. Numbers next to the tracks denote time as a day number: see Table 1 for control information. The quality of the position fixes for LR1 varied considerably: solid lines indicate good quality; solid squares, intermediate quality; dashes, poor quality. 


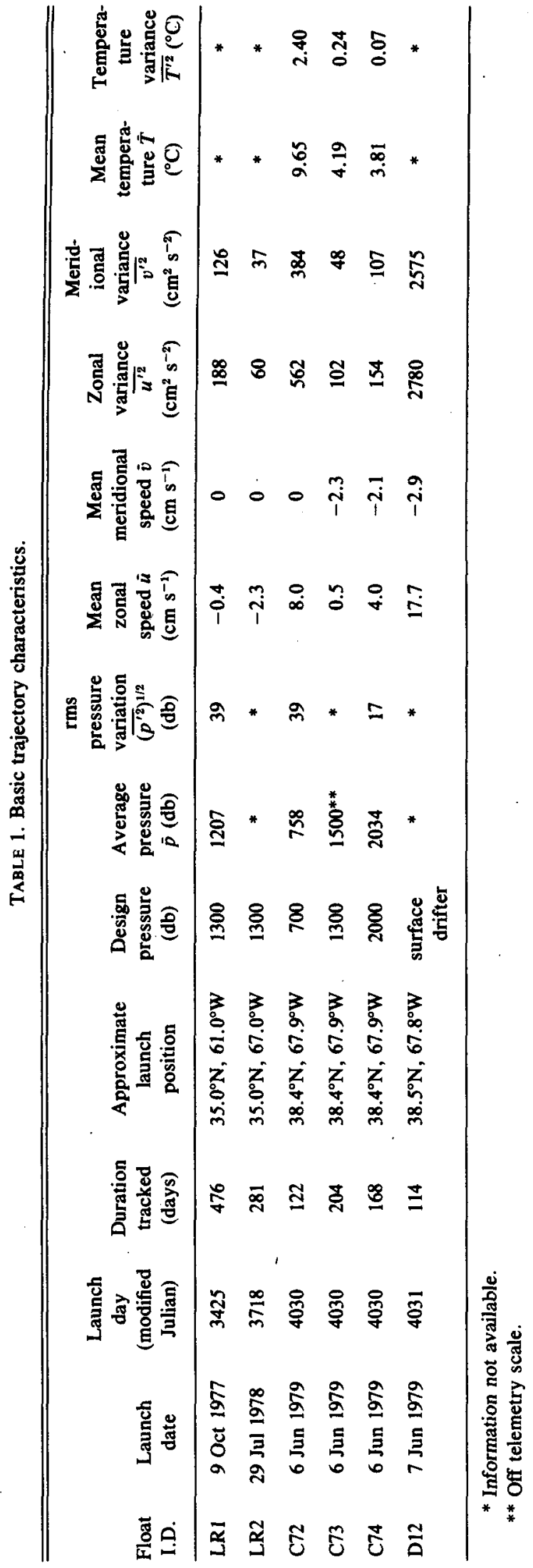

by the New England Seamounts (Richardson, 1981) and the Corner Rise (Richardson, 1980). A drifter that traversed the Kuroshio System showed similar sensitivity to topography (Cheney et al., 1980). The influence of topography on the float and drifter trajectories described in the following is in general reminiscent of Richardson's results with drifters.

Worthington's division (1976) of the subtropical gyre circulation outside of the Gulf Stream into two scales of motion with one confined roughly to latitudes north of Bermuda (most prominently at abyssal depths), here called the recirculation, has been independently substantiated (Schmitz, 1976, 1977, 1978, 1980). However, Worthington's (1976) hypothesis of an ageostrophic recirculation (at the leading order of approximation) has been shown by Stommel et al. (1978) to be unnecessary, and even another type of geostrophic recirculation has been suggested by Schmitz (1980). The combination of the Gulf Stream and recirculation will be referred to as the Gulf Stream System. The circulation in the subtropical gyre south of the recirculation will be called the return flow. In the following, we will use the nomenclature referred to in the previous sentences in this paragraph, but without implying adherence to all elements of the circulation model proposed by Worthington (1976). Fofonoff (1981) has recently summarized the nomenclature and status of knowledge of the structure of the Gulf Stream System.

\section{Discussion}

SOFAR floats (and surface drifters) are nearly isobaric rather than isopycnic, and hence a float track is not an exact water particle path. The spirit of our treatment and discussion of this type of quasiLagrangian data is in terms of mobile current sensors rather than literal water particle path-sensing devices, in some analogy to the approach taken by Freeland et al. (1975). The statistics that we compute are then simply mixed spatial and temporal averages. This paragraph contains our working version of the term "quasi-Lagrangian".

The floats signal three times each day. Position data are smoothed with a 2-day half-width Gaussian taper, and center-differenced to yield velocity. Signal detection and processing details, along with associated errors, have been described by Spain $e t$ al. (1980). Position errors are $\sim 5 \mathrm{~km}$, with a fix-to-fix random error of $\sim 1 \mathrm{~km}$. In addition, changes in tracking net due to changes in choice of listening station net are persistently observed to lead to position changes of $10 \mathrm{~km}$. We also have significant signal dropout and more serious tracking errors when operating at the limit of signaling reception range. The net velocity error is frequency dependent, being higher at higher frequencies, and the relative velocity error is displacement dependent. 
Preparation for gyre-scale exploration with SOFAR floats included tests of ALS tracking capability in the most energetic segments of the North Atlantic, including the Gulf Stream System. These data form the basis of the present investigation (Table 1). The initial engineering test float, called Long-Range 1 (LR1), was set in the recirculation area in 1977. LR2 was deployed $6^{\circ}$ longitude to the west about nine months later (Fig. 1, Table 1). LR1 yielded the longest term trajectory obtained in our test sequence, being followed for roughly 16 months over a wide range of positions, although with varying tracking quality, in the vicinity of the Gulf Stream System and in Slope Water. The performance of LR1 and LR2 indicated that the range $(\sim 2000 \mathrm{~km})$ needed for deployments on basin scale with a manageable number of receiving stations was achievable with some additional modifications. After redesign based on the experience gained with LR1 and LR2, as well as evaluations of an evolving ALS configuration, additional trials (involving ALS's on both sides of the Stream) were implemented in June 1979. This test sequence was initiated with the deployment of fioats G72, G73 and G74 (G denotes Gulf Stream) at a location $25-35 \mathrm{~km}$ south of the Stream axis (as determined by XBT data) in the vicinity of $38^{\circ} \mathrm{N}$. A satellite-tracked surface drifter (D12) was launched at about the same time and location. This drifter was located using data from Nimbus 6 (or F) and was deployed with $35 \mathrm{~m}$ of line between the drifter hull and a window-shade drogue. Basic data for the floats and surface drifter launched in the Gulf Stream are listed in Table 1 and trajectories shown in Figs. 2 and 3. For reference, the mean position of the $15^{\circ} \mathrm{C}$ isotherm at $200 \mathrm{~m}$ (from Schroeder, 1963), used as an index for the Stream axis (Fuglister and Voorhis, 1965), is plotted in Fig. 4 on the same scale as in Figs. 1-3. Bottom topographic contours on Figs. 1-4 were taken from Uchupi (1971); Fig. 4 contains bathymetric detail that was suppressed in Figs. 1-3 in order to present a relatively unencumbered visualization of float and drifter trajectories.

The trajectories in Figs. 1-3 illustrate a complexity consistent with existing Eulerian data (Hendry, 1981; Luyten, 1977; Schmitz, 1976, 1977, 1978, '1980) which typically yield eddy kinetic energies larger than the mean at abyssal depths in the vicinity of the Gulf Stream. At the lowest frequencies, LR1 is circulating cyclonically (Fig. 1), appearing to "cross" or "go through" the Gulf Stream at least twice. While in the Slope Water region, the mean flow for LR1 is to the west, agreeing with all (even moderately) long-term moored instrument observations there, beginning with Webster (1969). However, this flow

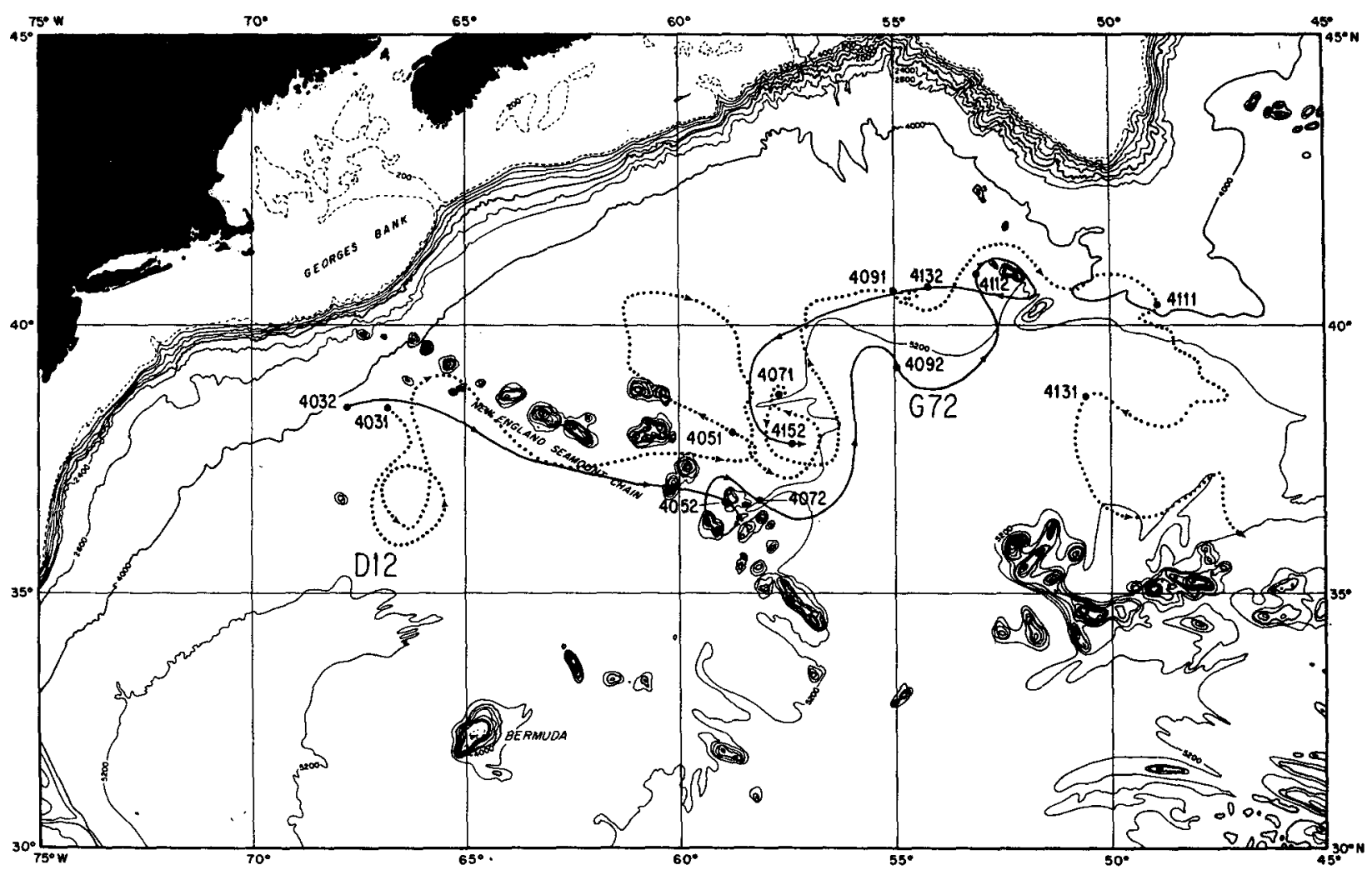

Fig. 2. Trajectories for float G72 and surface drifter D12. Numbers next to the tracks denote time as a day number: see Table 1 for control information. 


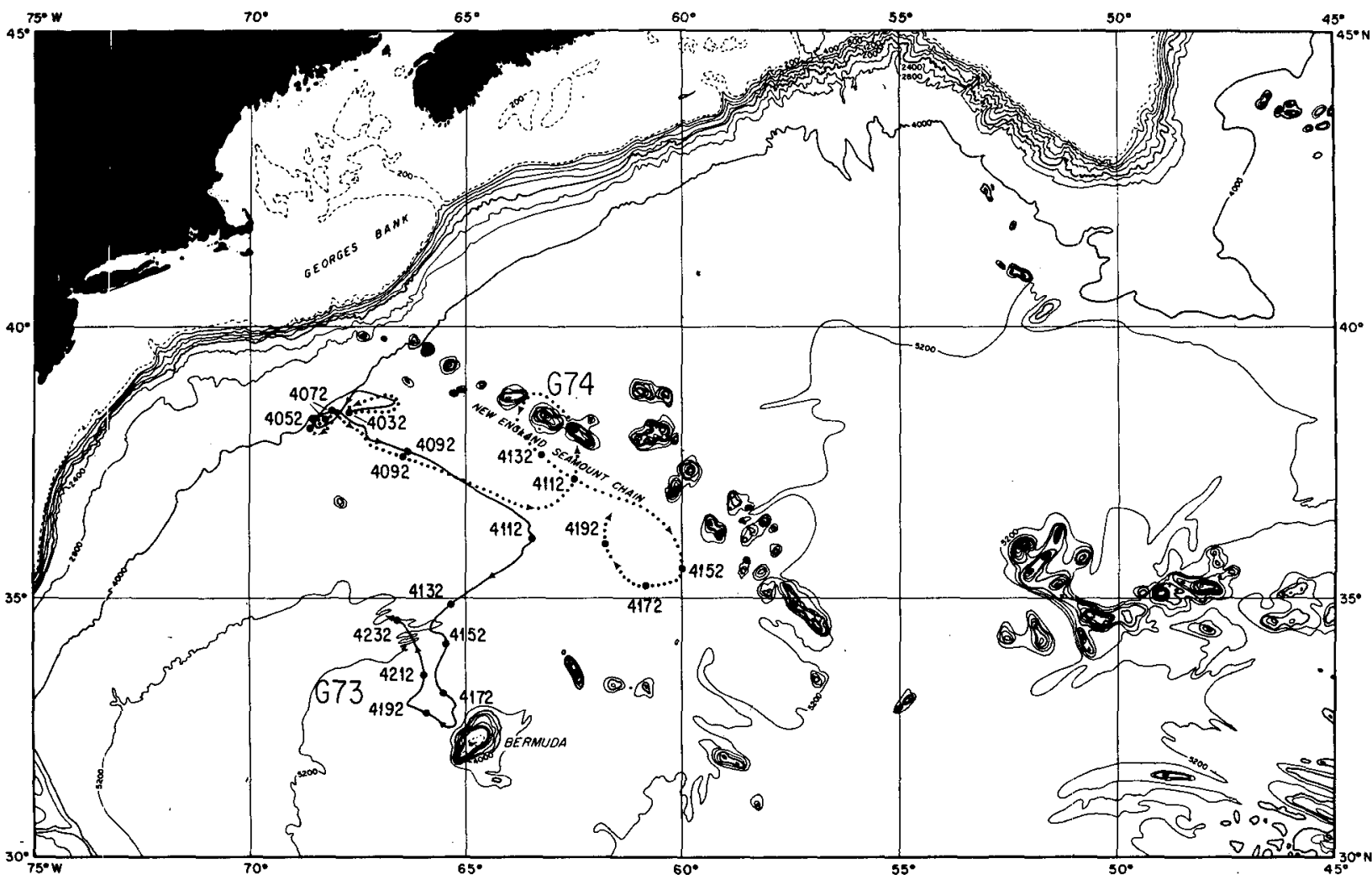

FIG. 3. Trajectories for floats G73 and G74. Numbers next to the tracks denote time as a day number: see Table 1 for control information.

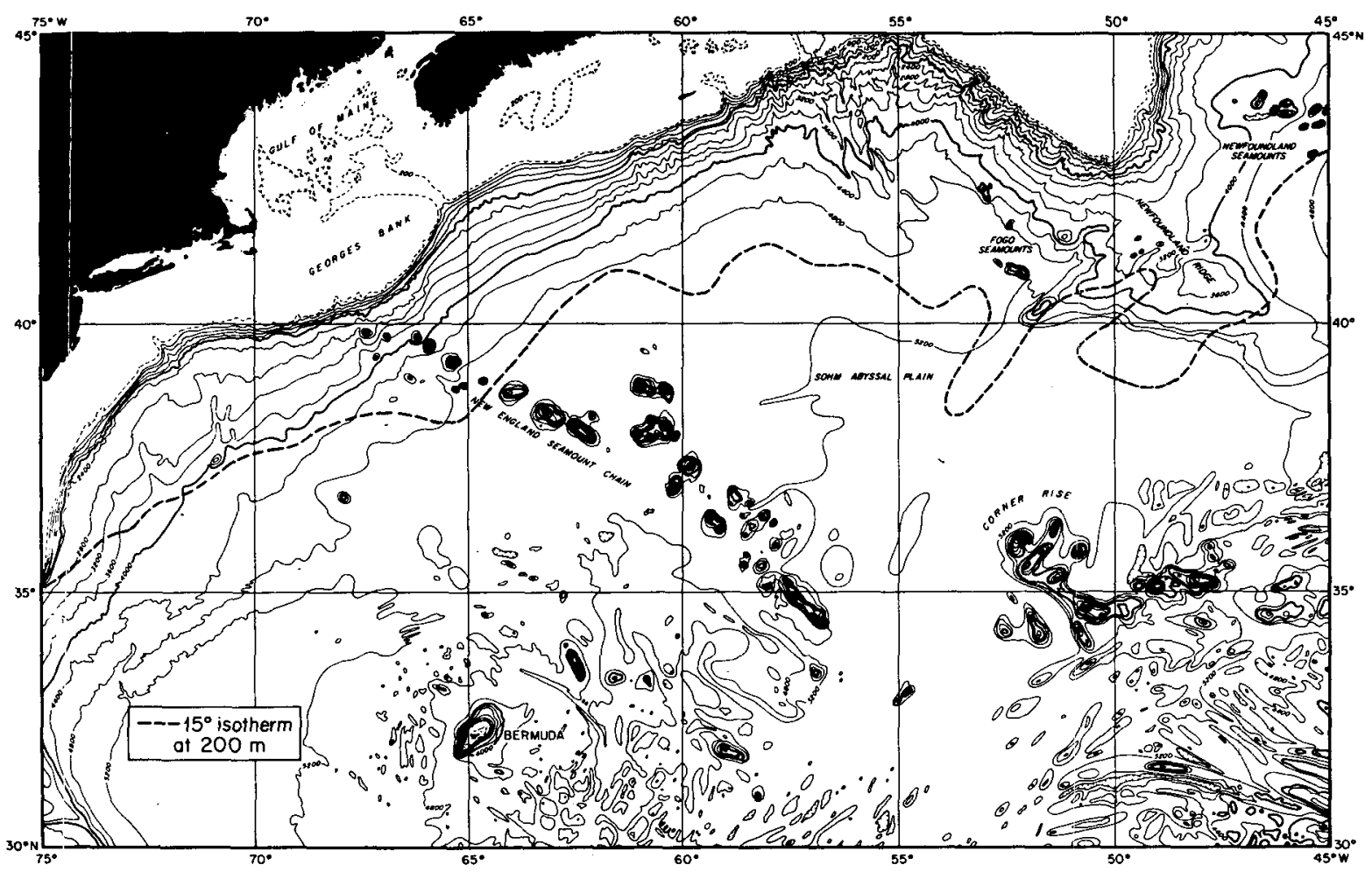

Fig. 4. Mean position of the $15^{\circ} \mathrm{C}$ isotherm at $200 \mathrm{~m}$ depth (according to Schroeder, 1963). 


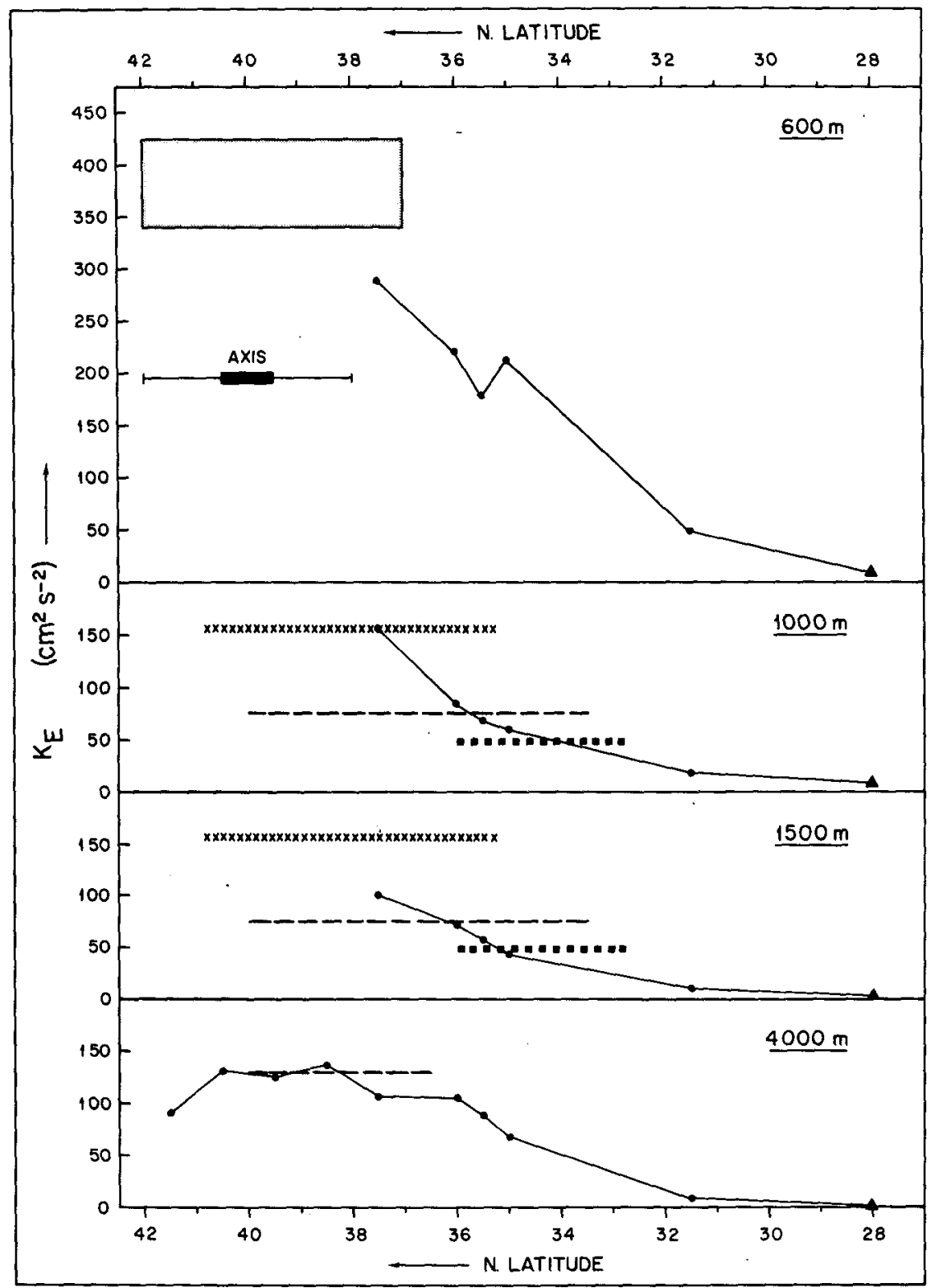

FIG. 5. Eddy kinetic energy $\left(K_{E}\right)$ as a function of latitude for Eulerian data for four depths along $55^{\circ} \mathrm{W}$ and for the floats in Figs. 1-3. The moored instrument data (Schmitz, 1978; Schmitz and Holland, 1981), located at the four depths shown to the right in each panel or frame, are connected by a solid line. Data for floats are denoted by: a dashed line in the $4000 \mathrm{~m}$ frame for G74; a dashed line for G73, solid squares for LR2, and crosses for LR1, all in both the 1000 and $1500 \mathrm{~m}$ panels; G72 by a shaded box in the $600 \mathrm{~m}$ frame. A range of positions for the axis of the Gulf Stream is shown in the upper panel: the solid bar is appropriate to $55^{\circ} \mathrm{W}$, the bracketed line spans the latitude range appropriate to the floats.

regime is not contained in Worthington's (1976) circulation diagrams. LR1 moves both west and east while near the expected location of the Gulf Stream, reminiscent of Eulerian data. LR2 exhibits the "expected" behavior for the recirculation regime, moving westward at a few centimeters per second on the average until reaching the vicinity of the Gulf Stream and Cape Hatteras, where tracking was lost due to shore-based listening station failure. The thermocline float (G72) and surface drifter launched near $67-68^{\circ} \mathrm{W}$ in the Gulf Stream (Fig. 2) move in a relatively coherent pattern on the largest scale for $\sim 70$ days over about $1300 \mathrm{~km}$, evidently staying in the vicinity of a visually clear-cut Stream until in the vicinity $\left(52-53^{\circ} \mathrm{W}\right)$ of the Fogo Seamounts (Fig. 4). G72, which telemetered temperature, traversed 
much colder water after leaving the Fogo Seamounts, as expected in Slope Water where the temperature at the float was observed to be $\sim 6^{\circ} \mathrm{C}$, in contrast to $10-12^{\circ} \mathrm{C}$ while in the Gulf Stream. Although D12 and $G 72$ both moved south of east along the New England Seamounts, and looped north to the Fogo Seamounts, their intermediate horizontal-scale behavior is not similar. The early cyclonic movement of D12 was due to the presence of a documented ring (Cummings et al., 1979). D12 is apparently also influenced by a meander-ring pattern near about 56$61^{\circ} \mathrm{W}$ [also seen in the temperature field by Blumenthal and Gotthardt (1979) and by Cummings et al. (1979)]. None of this is exhibited in any detail by the G72 trajectory, although there is a connection to a meander pattern on the largest scale in the vicinity of $56-61^{\circ} \mathrm{W} . \mathrm{G} 73$ and G74 also moved coherently over the first 70-80 days of their deployment (Fig. 3), and, after initially being caught in a small-scale feature not exhibited by G72, moved in the same direction as $\mathrm{G} 72$ but at a slower speed. All floats as well as the surface drifter were noticeably affected by the New England Seamounts, much as previously observed and described by Richardson
(1981), and perhaps rationalized to some extent by Owens and Hogg (1980). The tracks for G73 and G74 diverge sharply from each other as well as from the tracks of G72 and D12 in the vicinity of the New England Seamount Chain, with neither deep float clearly crossing the seamounts like the upper level drifters. The trajectory from the vicinity of the New England Seamounts for float G74 (Fig. 3) is reminiscent of the trajectory of LR1 (Fig. 1) while the latter was in the same region. The sum of the trajectories for LR1, G73 and G74 may imply that the abyssal flow in the vicinity of the Gulf Stream does not penetrate (is blocked), or only partially penetrates (is to some extent blocked) east of the New England Seamounts. Other evidence for this type of flow regime is discussed by Schmitz (1980) and Richardson (1981, see especially Fig. 2).

Basic statistics for the trajectories are contained in Table 1. Eddy kinetic energies are shown in Fig. 5, and zonal and meridional variances in Figs. 6 and 7. The float statistics in Figs. 5, 6 and 7 are plotted along with the only existing latitudinal section (at $55^{\circ} \mathrm{W}$ ) of Eulerian time averages at both abyssal and thermocline depths (Schmitz, 1978; an

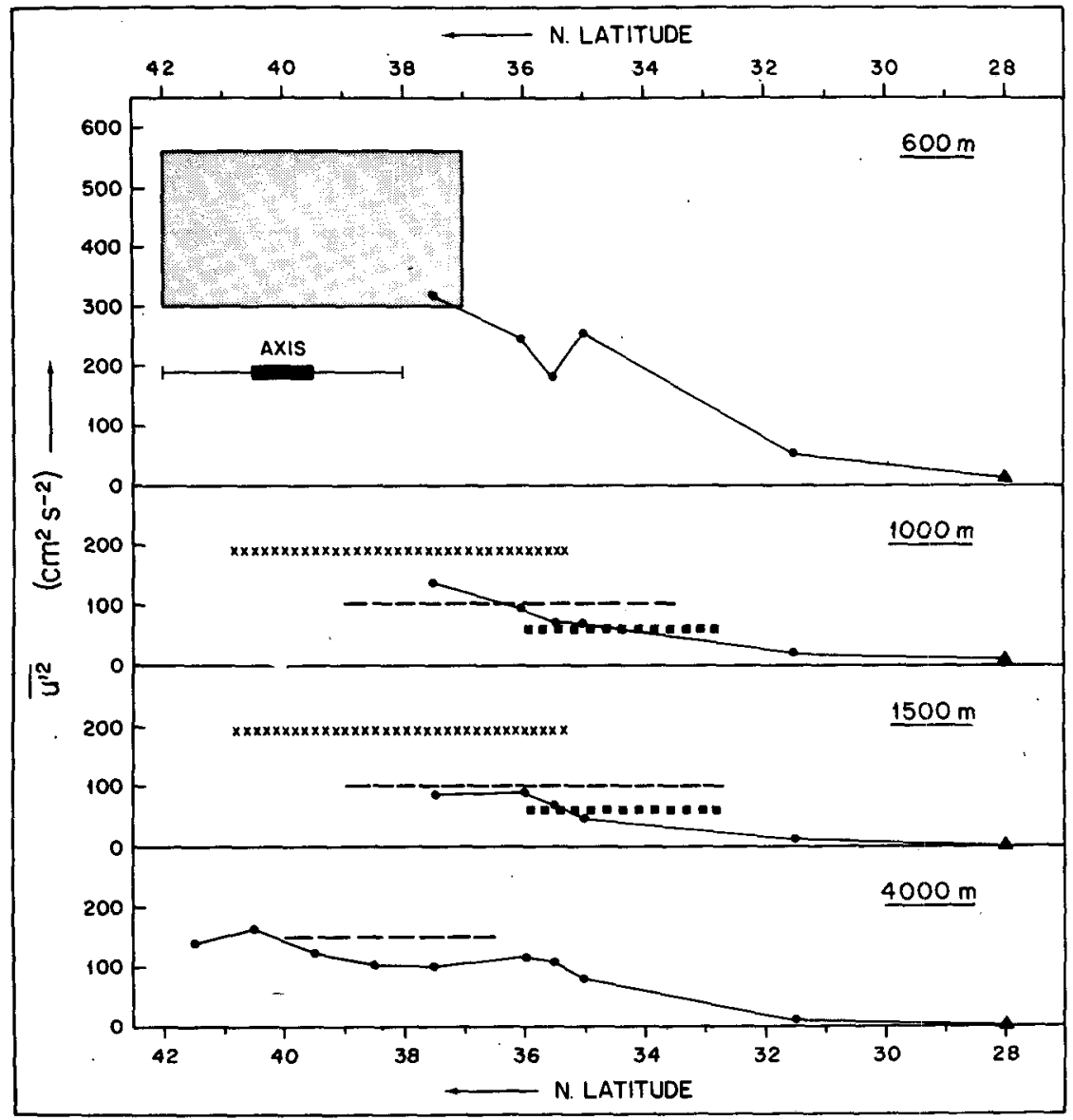

FIG. 6. As in Fig. 6 except for zonal variance $\left(\overline{u^{\prime 2}}\right)$. 


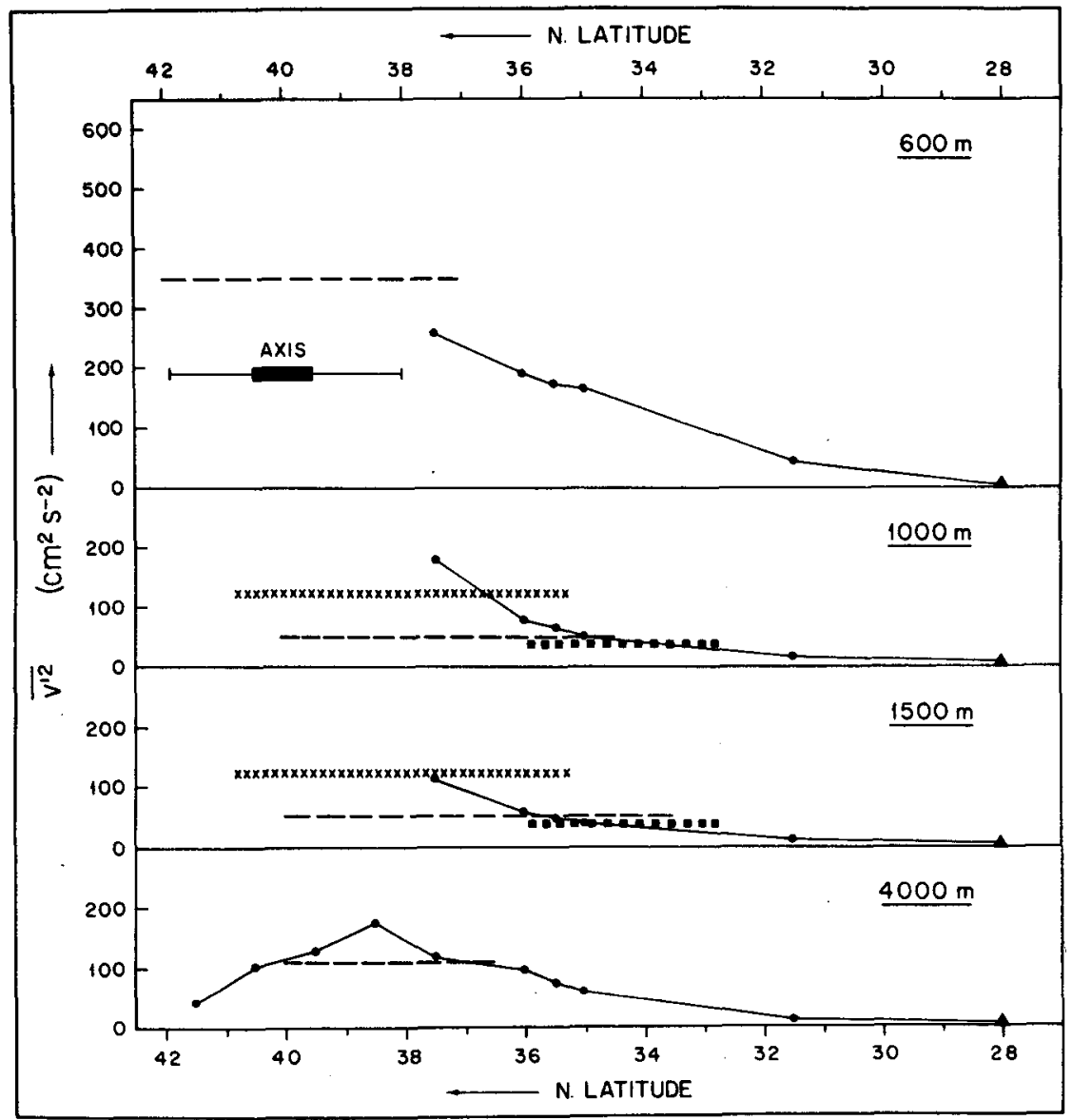

FIG. 7. As in Fig. 6 except for meridional variance $\left(\overline{v^{\prime 2}}\right)$.

updated version is contained in Schmitz and Holland, 1981; see, also, Hendry, 1981). The symbols $\overline{u^{\prime 2}}$ and $\overline{v^{\prime 2}}$ are used for zonal and meridional variances: $K_{E}=0.5\left(\overline{u^{\prime 2}}+\overline{v^{\prime 2}}\right)$. The prime denotes a deviation from the overbarred average (with this average taken along a trajectory for a quasi-Lagrangian quantity, in time at a point for Eulerian data). $\bar{u}$ and $\bar{v}$ denote zonal and meridional mean flows respectively. In Figs. 5-7, quasi-Lagrangian $K_{E}$ and variances are plotted as values that extend over the latitude range traversed by the floats, and in the case of the thermocline float $\mathrm{G72}$, also over the range of $K_{E}$ resulting from different plausible choices of averaging interval.

The float $K_{E}$ values in Fig. 5 are generally consistent with the Eulerian estimates, perhaps remarkably so, and this also holds true for the distributions of zonal and meridional variance in Figs. 6 and 7. LR1 results agree least with the Eulerian data, being generally higher. In the frequency distributions of Fig. 8 the only significant difference between the LR1 estimates and a comparable Eulerian distribution occurs for periods of 2-20 days. This period range is the primary locus of tracking noise [see also Fig. 10, p. 400 in Freeland et al. (1975)], expected to be relatively large for LR1, which operated at the limit of positioning range over much of its lifetime, and in general is the lowest quality track available. We examined the energy-frequency distribution for LR1 in some detail because it is the longest trajectory available, and therefore most appropriate for comparison with the lowest frequencies accessible with the Eulerian data. Float tracks for G72, G73 and LR2 are much shorter, although of higher tracking quality. However, stable spectral estimates for the highest frequency band (periods 2-20 days) are accessible with these floats, and result in energies that are considerably closer to the appropriate Eulerian estimates. For example, G73 yields $17 \mathrm{~cm}^{2} \mathrm{~s}^{-2}$ for 2-20 day periods (the Eulerian result for this frequency band in Fig. 8 is $\sim 18 \mathrm{~cm}^{2} \mathrm{~s}^{-2}$ ), as opposed to roughly $55 \mathrm{~cm}^{2} \mathrm{~s}^{-2}$ for LR1 (Fig. 8). $K_{E}$ values for the surface drifter D12 are in the vicinity of 2500 $\mathrm{cm}^{2} \mathrm{~s}^{-2}$, more than a factor of 2 higher than might be suggested from casual examination (the averaging schemes are different) of estimates from the map 


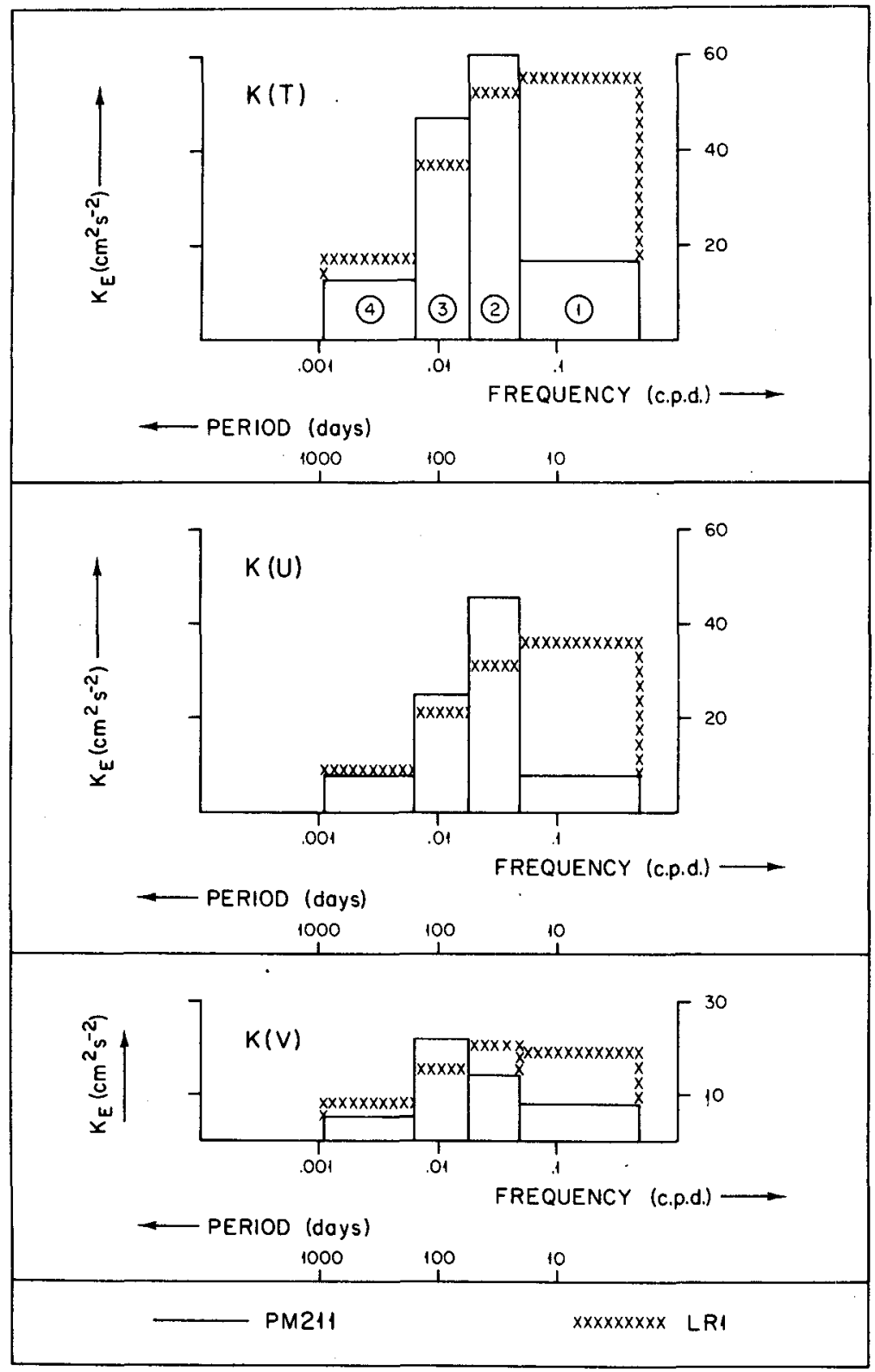

Fig. 8. Frequency distributions of eddy kinetic energy for $4000 \mathrm{~m}$ depth at $40^{\circ} 30^{\prime} \mathrm{N}, 55^{\circ} \mathrm{W}$ (PM211 is the label identifying this site) and for the longest float record (LR1). $K(T)$ denotes total $K_{E}, K(U)$ zonal, $K(V)$ meridional. The period ranges (nominal) for the four frequency bands plotted are: (1), 2-20 days; (2), 20-47 days; (3) , 47-157 days; (4), 157-940 days.

due to Wyrtki et al. (1976). These results for D12 [which are compatible with those reported by Kirwan et al. (1976) for another drifter] appear at the present time to be in fact indicative of averages over several drifters (Richardson et al., 1979; Richardson, 1980,1981$)$. Values of $\bar{u}$ for D12 and G72 (18 and $8 \mathrm{~cm} \mathrm{~s}^{-1}$, Table 1) are clearly appropriate to a space-time averaged Gulf Stream; averaged over a few days speed values reach 3 and $1 \mathrm{kt}$, respectively.

\section{Summary and conclusions}

One picture of the North Atlantic circulation (Worthington, 1976) hypothesizes (implicitly) a vertically coherent Gulf Stream, more or less always present at all depths, although of course executing meanders and forming rings at various times and locations. The Lagrangian observations presented support this picture at depths in the thermocline 
and above, but not necessarily below, in qualitative agreement with the Eulerian data available.

The estimate of $\sim 400 \mathrm{~cm}^{2} \mathrm{~s}^{-2}$ for $K_{E}$ in the thermocline ( $700 \mathrm{~m})$ in the Gulf Stream west of the Grand Banks is the first such direct measurement to the best of our knowledge. It is compatible with extrapolation of existing Eulerian data. $K_{E}$ estimates from the upper layers of the western (energetic) segment of the Kuroshio Extension (Nishida and White, 1981) are roughly $200-300 \mathrm{~cm}^{2} \mathrm{~s}^{-2}$. Such estimates for both of these midlatitude jets are noticeably lower than results from the upper layer of several existing numerical model runs (Holland, 1978; Schmitz and Holland, 1981). All but one Lagrangian estimate of perturbation kinetic energies below the thermocline are nearly identical to existing Eulerian estimates. The one discrepancy is shown to be dominated by differences in the highest frequency band (periods of 2-20 days), the expected locus of error in float positioning. The compatibility of this initial comparison of quasi-Lagrangian and Eulerian observations at abyssal depths near the Gulf Stream should remove any lingering doubts as to the complexity of this flow field.

Acknowledgments. Support from the National Science Foundation under Grants OCE7.8-18007 to the Woods Hole Oceanographic Institution and OCE79-17901 to the University of Rhode Island is gratefully acknowledged. H. Stommel and an anonymous reviewer made helpful recommendations. This is Contribution No. 4759 from the Woods Hole Oceanographic Institution and Contribution No. 156 from the Open Ocean Dynamics Experiment, POLYMODE.

\section{REFERENCES}

Blumenthal, B. P., and G. A. Gotthardt, 1979: Formative stages of a cyclonic Gulf Stream Ring. Gulfstream, 7, p3. Monthly summary for July 1979. U.S. Dept. of Commerce.

Bradley, A., 1978: Autonomous Listening Stations POLYMODE News No. 8, Woods Hole Oceanographic Institution, (unpublished document).

Cheney, R. E., P. L. Richardson and K. Nagasaka, 1980: Tracking a Kuroshio cold core ring with a free-drifting surface buoy. Deep-Sea Res., 27, 641-654.

- W. H. Gemmill, M. K. Shank, P. L. Richardson and D. Webb, 1976: Tracking a Gulf Stream Ring with SOFAR floats. J. Phys. Oceanogr., 6, 741-749.

Clarke, R. A., H. W. Hill, R. F. Reiniger and B. A. Warren, 1980: Current system south and east of the Grand Banks of Newfoundland. J. Phys. Oceanogr., 10, 25-65.

Crease, J., 1962: Velocity measurements in the deep water of the western North Atlantic. J. Geophys. Res., 67, 3173-3176.

Cummings, B. B., G. A. Gotthardt and R. L. Barrett, 1979: Aircraft observations of meander development and ring formation. Gulfstream, 8, 6-7. Monthly summary for August 1979, U.S. Dept. of Commerce.

Fofonoff, N. P., 1967: Measurement of ocean currents. Selected
Papers from the Governor's Conference on Oceanography, Rockefeller University, New York, 95-107.

_- 1981: The Gulf Stream System. Evolution of Physical Oceanography, Scientific Surveys in Honor of Henry Stommel, The MIT Press, 112-139.

Freeland, H. F., P. B. Rhines and H. T. Rossby, 1975: Statistical observations of the trajectories of neutrally buoyant floats in the North Atlantic. J. Mar. Res., 33, 383-404.

Fuglister, F. C., 1963: Gulf Stream '60. Progress in Oceanogr., Vol. 1, Pergamon, 1, 265-373.

- , and A. D. Voorhis, 1965: A new method of tracking the Gulf Stream. Limnol. Oceanogr., 10(Suppl.), R115-124.

Hendry, R., 1981: On the structure of the deep Gulf Stream. Submitted to J. Mar. Res.

Holland, W. R., 1978: The role of mesoscale eddies in the general circulation of the ocean-numerical experiments using a wind-driven quasi-geostrophic model. J. Phys. Oceanogr., 8, 363-392.

Kirwan, A. D., Jr., G. McNally and J. Coehlo, 1976: Gulf Stream kinematics inferred from a satellite-tracked drifter. J. Phys. Oceanogr., 6, 750-755.

Luyten, J. R., 1977: Scales of motion in the deep Gulf Stream and across the continental rise. J. Mar. Res., 35, 49-74.

McDowell, S. E., and H. T. Rossby, 1978: Mediterranean Water: An intense mesoscale eddy off the Bahamas. Science, 202, 1085-1087.

McWilliams, J. C., 1976: Maps from the Mid-Ocean Dynamics Experiment. J. Phys. Oceanogr., 6, 810-846.

Nishida, H., and W. B. White, 1981: On the role of eddy processes in the momentum and kinetic energy balance of the Kuroshio Extension. Submitted to J. Phys. Oceanogr.

Owens, W. B., and N. G. Hogg, 1980: Oceanic observations of stratified Taylor columns near a bump. Deep-Sea Res. 27, $1029-1045$.

Price, J. F., and H. T. Rossby, 1981: Observations of a planetary wave during the local dynamics experiment. Submitted to J. Mar. Res., 39 (in press).

Richardson, P. L., 1980: Anticyclonic eddies generated near the Corner Rise seamounts. J. Mar. Res., 38, 673-686.

-, 1981: Gulf Stream paths measured with free-drifting buoys. J. Phys. Oceanogr., 11 (in press).

— J. J. Wheat and D. Bennett, 1979: Free drifting buoy trajectories in the Gulf Stream system (1975-1978). A data report. Woods Hole Oceanogr. Inst. Tech. Rep., WHOI Ref. No. 79-4, 159 pp.

Riser, S. C., H. Freeland and H. T. Rossby, 1978: Mesoscale motions near the deep western boundary of the North Atlantic. Deep-Sea Res., 25, 1179-1191.

—, and H. T. Rossby, 1981: Quasi-Lagrangian structure and variability of the subtropical western North Atlantic circulation. Submitted to J. Mar. Res.

Rossby, H. T., A. D. Voorhis and D. Webb, 1975: A quasiLagrangian study of mid-ocean variability using long range SOFAR floats. J. Mar. Res., 33, 355-382.

- , and D. Webb, 1970: Observing abyssal motions by tracking Swallow floats in the SOFAR channel. Deep-Sea Res., 17, 359-365.

Schmitz, W. J., Jr., 1976: Eddy kinetic energy in the deep western North Atlantic. J. Geophys. Res., 81, 4981-4982.

, 1977: On the deep general circulation in the western North Atlantic. J. Mar. Res., 35, 21-28.

- 1 1978: Observations of the vertical structure of low-frequency fluctuations in the western North Atlantic. J. Mar. Res., 36, 295-310.

-, 1980: Weakly depth-dependent segments of the North Atlantic circulation. J. Mar. Res., 38, 111-113.

- A. R. Robinson, and F. C. Fuglister, 1970: Bottom velocity observations directly under the Gulf Stream. Science, 170, $1192-1194$. 
and W. R. Holland, 1981: A preliminary comparison of selected eddy-resolving general circulation experiments with observation. Accepted for publication in J. Mar. Res.

Schroeder, E. H., 1963: North Atlantic temperatures at a depth of 200 meters. Serial Atlas Marine Environment, Folio 2, Amer. Geogr. Soc.

Spain, D. L., R. M. O'Gara, and H. T. Rossby, 1980: SOFAR flost data report of the POLYMODE Local Dynamics EXperiment. University of Rhode Island, Graduate School of Oceanography, Tech. Rep. 80-1, 200 pp.

Stommel, H., 1965: The Gulf Stream: A Physical and Dynamical Description, 2nd ed. University of California and Cambridge University Press, 248 pp.

_- P. Niiler and D. Anati, 1978: Dynamic topography and recirculation of the North Atlantic. J. Mar. Res., 36, 449468.

Swallow, J. C., 1955: A neutral-buoyancy float for measuring deep currents. Deep-Sea Res., 3, 74-81.
_- 1957: Some further deep current measurements using neutrally-buoyant floats. Deep-Sea Res., 4, 93-104.

—, 1971: The ARIES current measurements in the western North Atlantic. Phil. Trans. Roy. Soc. London, A270, 451460.

- , and L. V. Worthington, 1961: An observation of a deep countercurrent in the western North Atlantic. Deep-Sea Res., 8, 1-19.

Uchupi, E., 1971: Bathymetric Atlas of the Atlantic, Caribbean, and Gulf of Mexico. Woods. Hole Oceanogr. Inst. Tech. Rep., WHOI Ref. No. 71-71, 10 pp.

Webster, F., 1969: Vertical profiles of horizontal ocean currents. Deep-Sea Res., 16, 85-98.

Worthington, L. V., 1976: On the North Atlantic circulation. The Johns Hopkins Oceanogr. Stud., No. 6, 110 pp.

Wyrtki, K., L. Magaard and J. Hager, 1976: Eddy energy in the oceans. J. Geophys. Res., 81, 2641-2646. 